\title{
Quantum-chemical study of geometric and energy characteristics of some bases of shiff gossipol
}

Khaitbaev Kh. Alisher*, Toshov S. Khamza, Yuldashev Sh. Ikbol

Department Chemistry of natural compounds, Faculty of Chemistry National University of Uzbekistan, Tashkent. Uzbekistan

\section{A R T I C LE INFO}

\section{Article history:}

Received: 12 January 2019

Accepted: 20 January 2019

Available online: 27 January 2019

Manuscript ID: PCBR-1810-1018

\section{G RA P H I C A L A B S T R A C T}

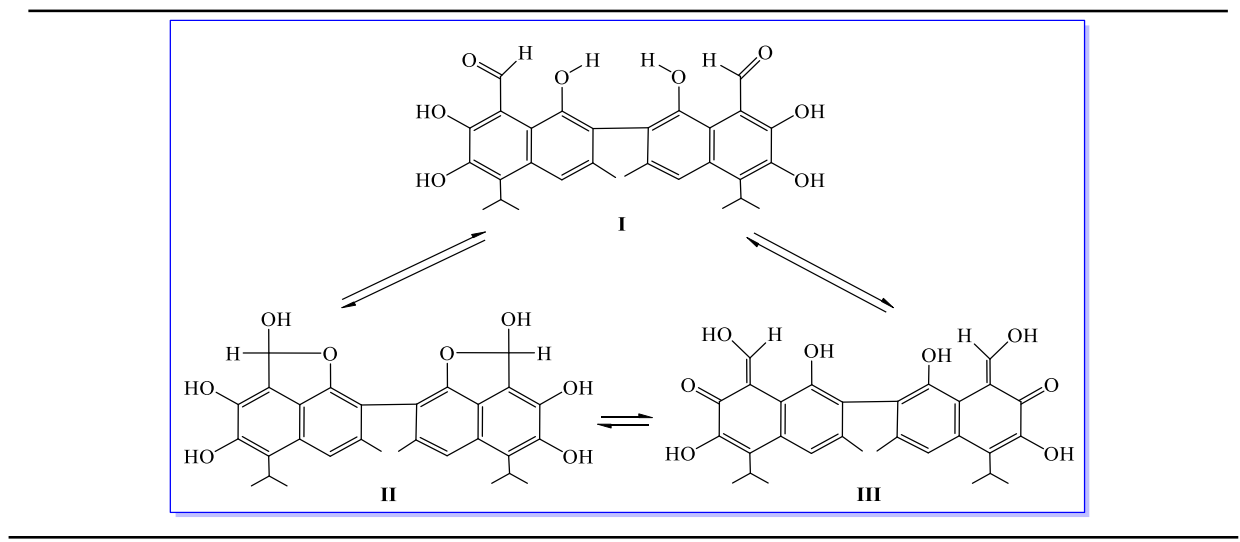

A B S T R A C T

The most important aspect of modern chemistry lies in the fact that along with instrumental (physical) methods, computer modelling plays an increasing role in it. The role of molecular modelling in chemistry is quite large, despite the obvious priority of experimental research in this field of natural science. The most significant ones are theoretical results that are impossible, extremely difficult or too expensive to be obtained by experimental means.

\section{Introduction}

Many plants contain phenolic compounds in their composition. The biological activity of many plants depends on the quantitative composition of the phenolic compounds in them [1].
One of these phenolic compounds of plants is gossypol. On the basis of gossypol itself and some of its derivatives, a number of antiviral drugs (3\% gossypol liniment, 3\% megosin ointment, tablets gozalidona, ragosina, mebavin) was created [2].

It is known that gossypol is characterized by tautomeric forms (Graphical Abstract): I, II, and III [3]. 
The total energies of these tautomeric forms are very close [4].

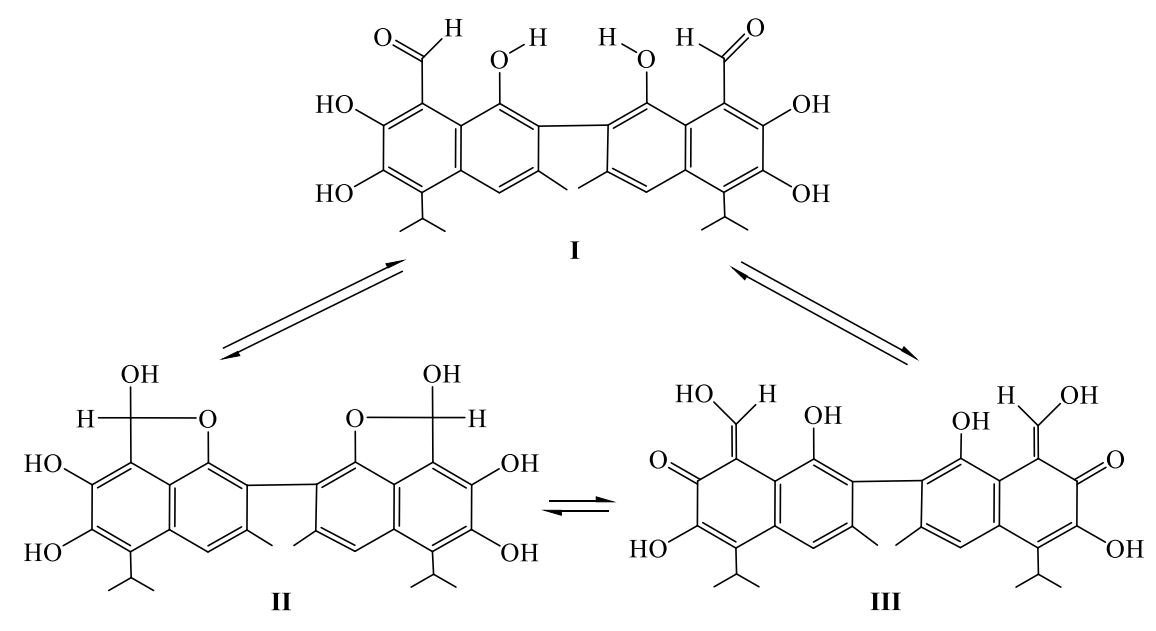

Fig. 1. Tautomeric forms of gossypol

The transition from one form to another has been thoroughly studied by the ${ }^{1} \mathrm{H}$ spectral method [5]. The transition from form I to III can be carried out by proton transfer from the $\mathrm{OH}$ group to the oxygen atom of the $\mathrm{C}=$ 0 group, depending on external factors or the nature of the solvent.<smiles>[R]N=Cc1c(O)c(O)c(C(C)C)c2cc(C)c(-c3c(C)cc4c(C(C)C)c(O)c(O)c(C=N[R])c4c3O)c(O)c12</smiles>

Similarly, gossypol derivatives with different amino compounds (Schiff bases) form two tautomeric - imineimine (IV) and enamine-enamine (V) forms.

Fig. 2. Tautomeric forms of Schiff gossypol bases

To study the tautomeric forms of gossypol derivatives, scheme for the synthesis of the Schiff base gossypol can be 3-aminopropanol-1 (VI), aniline (VII), 2,5-xylidine (VIII) represented using the following scheme: and benzidine (IX) were used as synthons. The general

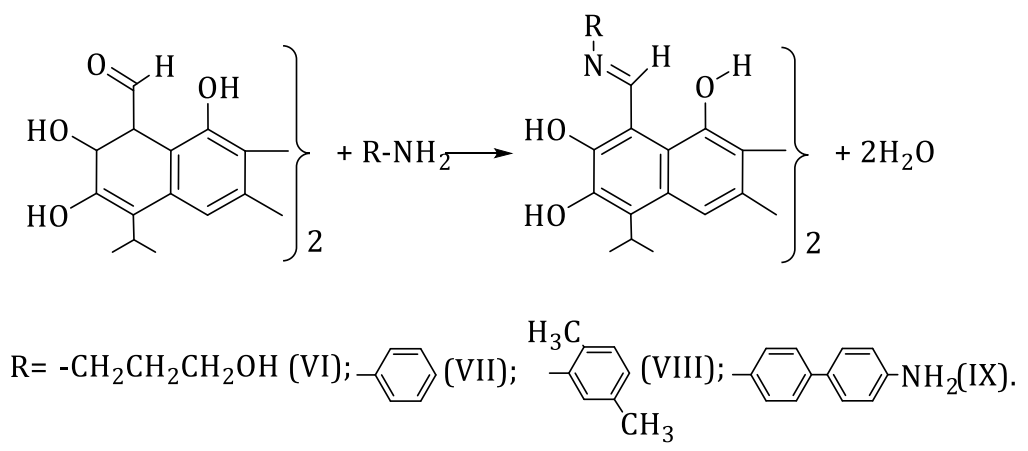

Scheme 1. general scheme for the synthesis of the Schiff base gossypol

\section{Experimental}

Of these compounds, only gossypolidenaniline (VII) was studied by X-ray diffraction (X-ray diffraction analysis) by the method, and the existence of this molecule in the crystal in the enamine-enamine (V) form was determined [6]. The presence of a phenyl substituent 
conjugated with a naphthalene nucleus leads to a significant redistribution of electron density over the entire molecule and a change in the energy characteristics of Schiff bases relative to the gossypol molecule.

In this connection, the energy characteristics of the above Schiff bases were considered using quantum chemical calculations using the semiempirical methods RM1, PM6 and PM7 in the MOPAC2012 software package [7]. To calculate the barrier of transition from one tautomeric form to another, the geometries of the intermediate structure of gossypol (aldehyde - ketolic form) and Schiff bases (imine-enamine form) were constructed.

\section{Results and Discussion}

According to the obtained data, it is revealed that the aldehyde and ketol forms of gossypol have very close values of the heat of formations (Table 1 ). In the obtained calculations using the PM6 and PM7 methods, the aldehyde form is more stable than the ketol form by only 0.31 and $2.69 \mathrm{kcal} / \mathrm{mol}$, respectively. And when calculated by the RM1 method, the aldehyde form is more stable than the ketol form by $7.8 \mathrm{kcal} / \mathrm{mol}$ (Table 1 and Fig . 3).

Table 1. The heat of formations $(\Delta \mathrm{H}, \mathrm{kcal} / \mathrm{mol})$ of the tautomeric forms of gossypol (I, III) and the corresponding Schiff bases calculated by semi-empirical methods RM1, PM6 and PM7

\begin{tabular}{|c|c|c|c|}
\hline Tautomer & RM1 & PM6 & PM7 \\
\hline & \multicolumn{3}{|c|}{ Gossypol } \\
\hline aldehyde - aldehyde & -306.37 & -300.42 & -311.25 \\
\hline aldehyde -ketol & -302.44 & -300.26 & -309.93 \\
\hline \multirow[t]{2}{*}{ ketol-ketol } & -298.49 & -300.11 & $-308,56$ \\
\hline & \multicolumn{3}{|c|}{ 3-Aminopropanol-1 + Gossypol (VI) } \\
\hline imine imine & -307.01 & -301.72 & -314.82 \\
\hline imine enamine & -310.72 & -311.69 & -320.40 \\
\hline \multirow[t]{2}{*}{ enamine-enamine } & -314.32 & -320.04 & -325.63 \\
\hline & \multicolumn{3}{|c|}{ Aniline + Gossypol (VII) } \\
\hline imine imine & -153.73 & -142.76 & -157.41 \\
\hline imine enamine & -157.34 & -151.46 & -162.84 \\
\hline \multirow[t]{2}{*}{ enamine-enamine } & -161.36 & -160.21 & -168.32 \\
\hline & \multicolumn{3}{|c|}{ 2,5-Xylidine + Gossypol (VIII) } \\
\hline imine imine & -188.14 & -179.84 & -195.97 \\
\hline imine enamine & -191.69 & -188.09 & -200.90 \\
\hline \multirow[t]{2}{*}{ enamine-enamine } & -195.29 & -196.34 & -205.80 \\
\hline & \multicolumn{3}{|c|}{ Benzidine + Gossypol (IX) } \\
\hline imine imine & -124.16 & -102.32 & -116.28 \\
\hline imine enamine & $-127,81$ & -111.02 & -121.97 \\
\hline enamine-enamine & $-131,78$ & -119.74 & -127.70 \\
\hline
\end{tabular}


Unlike gossypol, for all Schiff bases, the stability of the enamine-enamine form (V) is characteristic, and the imine-imine (IV) form is approximately $12 \mathrm{kcal} / \mathrm{mol}$ (Table 1 and Fig. 4-7).

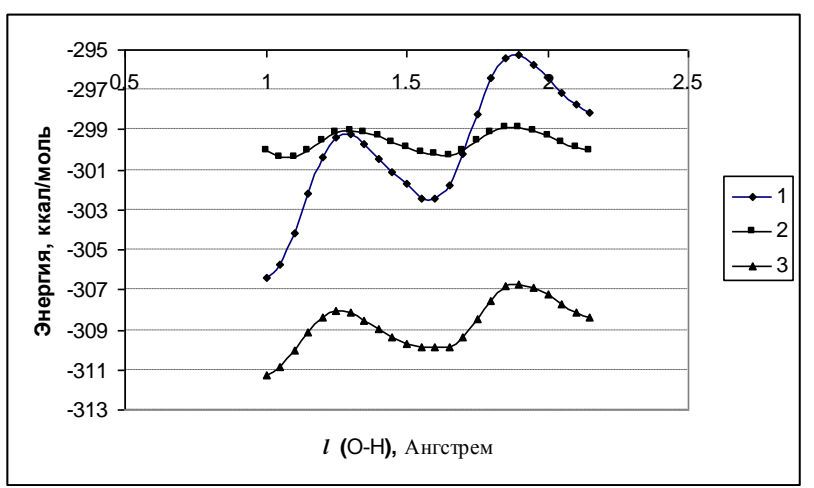

Fig. 3. Barrier transition from aldehyde-aldehyde to ketol-ketol form of gossypol. The semi-empirical RM1 (1), PM6 (2) and PM7 (3) methods

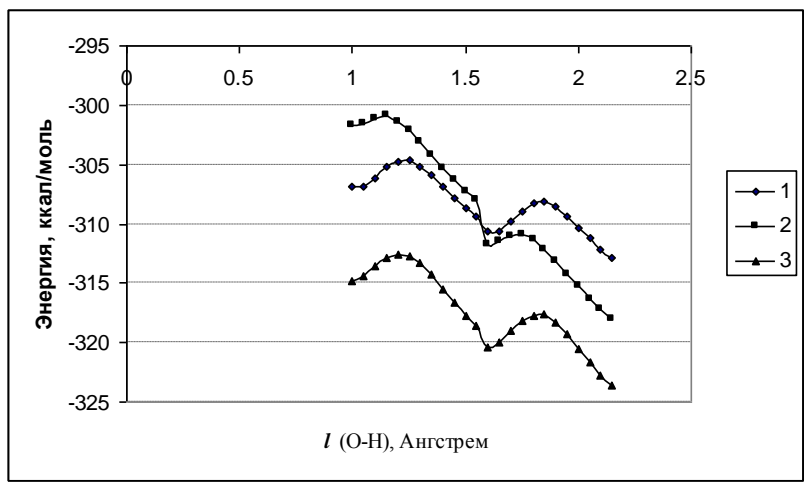

Fig. 4. Barrier transition from imine-imine (IV) forms to enamine-enamine form (V) of a Schiff-VI base by the methods RM1 (1), PM6 (2) and PM7 (3)

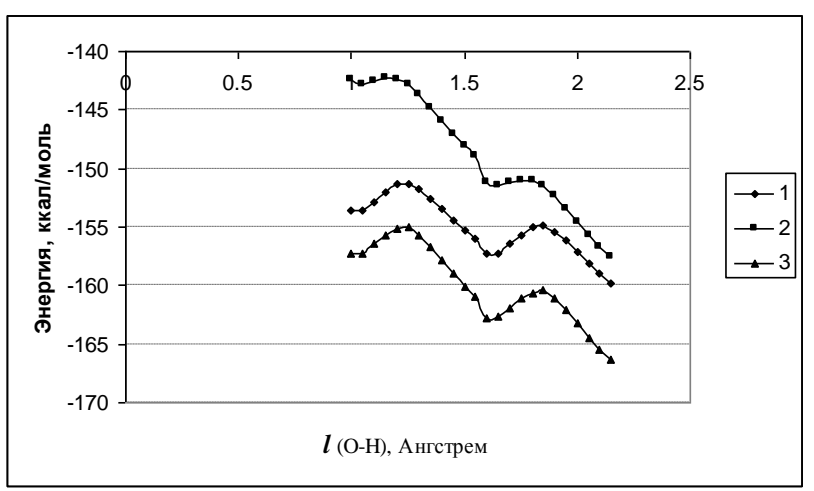

Fig. 5. Barrier transition from imine-imine (IV) forms to enamine-enamine form (V) of the Schiff base VII by the methods RM1 (1), PM6 (2) and PM7 (3)

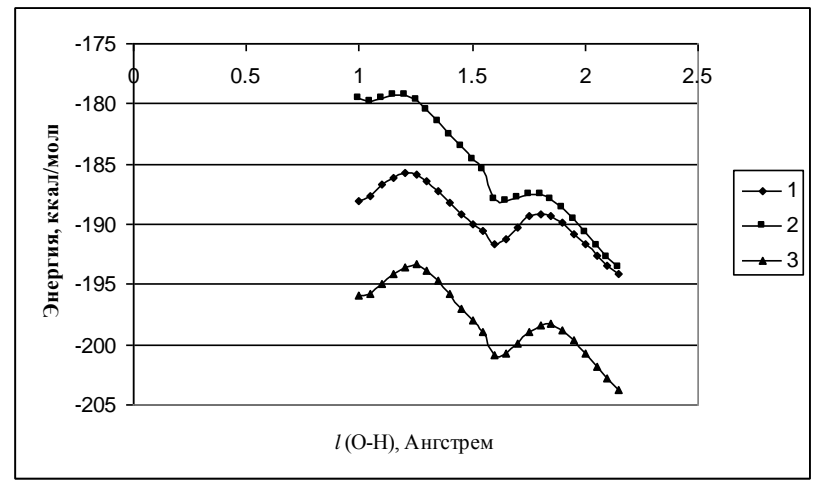

Fig. 6. Barrier transition from imine-imine (IV) forms to enamine-enamine form (V) of a Schiff-VIII base by the methods RM1 (1), PM6 (2) and PM7 (3)

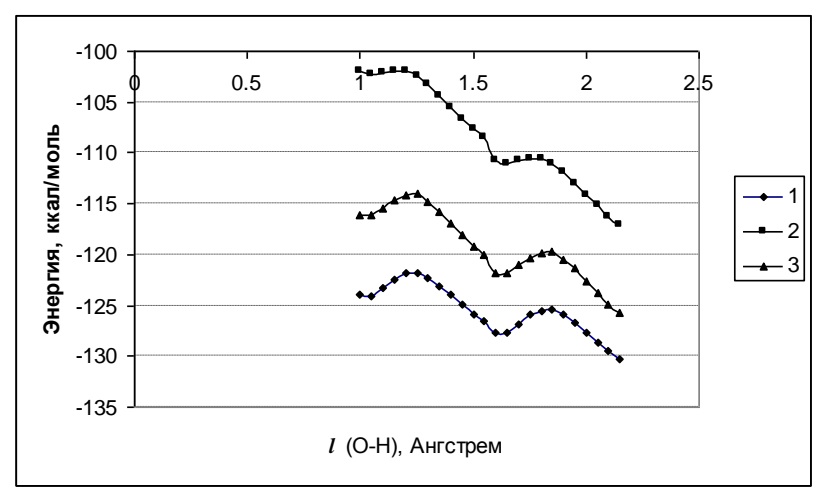

Fig. 7. Barrier transition from imine-imine (IV) forms to enamine-enamine form (V) of Schiff base IX by the methods RM1 (1), PM6 (2) and PM7 (3)

\section{Conclusion}

According to the obtained data, with the help of the calculation methods carried out, the following conclusion can be made:

- in the studied Schiff bases, the enamine-enamine form $(\mathrm{V})$ is optimal, independent of the radical $\mathrm{R}$ in structure V;

- the barrier of transition from imine-imine (IV) form to imine-enamine and, therefore, to enamine-enamine is 0.4-0.7 (PM6) and 2-2.6 (RM1 and PM7) kcal / mol, respectively;

- the barrier of transition from a stable form to an unstable form of Schiff bases ranges from 6 to $10.75 \mathrm{kcal} /$ mol. Whereas, for gossypol, the barrier of transition from 
an unstable form to a stable form is from 1.21 to $3.15 \mathrm{kcal}$ / mol.

\section{References}

[1] I. A. Samylina and G.P.Yakovlev, Pharmacognosy, 2013, Moscow. GEOTAR. Media, pp. 976

[2] N. I. Baram and A. I. Ismailov, Chemistry of Natural Compounds, 1993, 3, 334.
[3] A. I. Glushenkova and I. P. Nazarov, Gossypol, its derivatives and their use. 1993: Tashkent, Fan.

[4] M. A. Ashirmatov and N. D. Abdullaev, Chemistry of Natural Compounds, 1996, 2, 517.

[5] N. D. Abdullaev et al., Chemistry of Natural Compounds, 1990, 4, 166.

[6] G. B. Nazarov, B. T. Ibragimov, T. F. Aripov, Chemistry of Natural Compounds, 1988, 3, 661.

[7] J. P. Stewart. Mopac program package for Windows. www.openmopac.net. 